\title{
Hydrogen Peroxide Induced Oxidative Damage on Mineral Density and Mechanical Properties of Bone
}

\author{
Ekrem Cicek $^{1 *}$, Enes Cakmak ${ }^{2}$ \\ ${ }^{1}$ Mehmet Akif Ersoy University - Department of Physics Faculty of Art and Science, Burdur, Turkey; ${ }^{2}$ Suleyman \\ Demirel University - Department of Textile Engineering Isparta Turkey.
}

\begin{abstract}
Hydrogen peroxide is a common reactive oxygen species involved in the catalytic mechanism though it is toxic to cells due to its oxidative nature. This work investigates the effects of hydrogen peroxide induced oxidative damage on bone mineral density and mechanical properties of bone which is primarily a composite material composed primarily of collagen fibers and biominerals. Sheep leg bones were exposed to hydrogen peroxide for a week. Bone mineral density was measured by using dual energy X-ray absorptiometry. Compressive modulus tests were applied to bone in order to determine mechanical properties. Our study shows that the hydrogen peroxide induced oxidative stress has negative effects on bone mineral density and stiffness. We observed higher control curve slopes than that of hydrogen peroxide curves which account for lesser stiffness values in the exposed tissue ( $p<0.05)$.
\end{abstract}

Keywords: Bone mineral density, compressive modulus, hydrogen peroxide, reactive oxygen species

* Author for correspondence: ekrcicek@gmail.com 


\section{INTRODUCTION}

Bone is a metabolically active tissue that undergoes continuous remodeling via two counteracting processes, resorption and bone formation, which should be balanced in order to maintain bone mass and integrity ${ }^{1}$. Bone resorption, involving bone mineral degradation, is performed by osteoclasts ${ }^{2}$, while bone formation is performed by osteoblasts and osteocytes.

It is widely accepted that the increased amounts of the reactive oxygen species due to oxidative stress act in several degenerative conditions involving osteoporosis ${ }^{3,4}$, a degenerative disease characterized by decreased bone mineral density and leading cause of fractures in the elder ${ }^{5,6}$, and osteoarthritis. Hydrogen peroxide $\left(\mathrm{H}_{2} \mathrm{O}_{2}\right)$ is an unstable reactive oxygen species that can cause severe damage oxydizing DNA, protein and lipids ${ }^{6}$. A naturally occurring toxic product of peroxisome activity eliminated by catalase through peroxidation forming radicals, it is used in the prevention of local bacterial infection and clinical debridement in bone and joint surgeries ${ }^{7,8,9}$. In in vivo studies, increased levels of osteoclast activity were reported as a result of the overproduction of reactive oxygen species including hydrogen peroxide $^{10,11,12}$, eventually accelerating the bone loss ${ }^{13,14}$. Being membrane permeant and having a comparatively long half-life, hydrogen peroxide is known to stimulate osteoclast formation and function through resorptive sitokines ${ }^{15,16}$.

Bone matrix is a composite material comprising mainly of collagen and biominerals, latter formed majorly by crystalline hydroxyapatite, largely providing bone mechanical properties. Although mineral components are more effective on the strength and stiffness, brittleness observed at increased levels result in bone fragility ${ }^{17}$. The strongest predictor of bone mechanical strength ${ }^{18,19}$ is the bone mineral density (BMD) testing. A strong relation between BMD and fracture risk is identified clinically ${ }^{20}$. In a clinical fracture study ${ }^{21,22}$, it was reported that an increase of total hip BMD was associated with vertebral and non-vertebral fracture prevention ${ }^{18,21}$. Oxidative stress was proposed to be related with reduced bone mineral density (BMD), stiffness and strength ${ }^{10}$, and caused osteoporosis by in vitro studies ${ }^{16,22}$. However, the mechanisms through which bone matrix is affected are not clearly identified.

Although there are many studies related to various effects of hydrogen peroxide on bone structure ${ }^{1,15,16,18,23,24}$, hydrogen peroxide induced oxidative damage on the biomechanical properties of bone have not been subjected to detailed studies to date. The aim of this study is to make contribution to understanding the effects of hydrogen peroxide on the mineral density and compressive modulus in the sheep leg bone.

\section{MATERIALS AND METHODS}

Fresh sheep leg bones were obtained from a local abattoir within a few hours after slaughter (Burdur, Turkey). After removing the surrounding soft tissue, bone was cut into small pieces (a square with sides of length $20 \mathrm{~mm}$ ). Bone samples were placed inside $30 \% \mathrm{H}_{2} \mathrm{O}_{2}(300 \mathrm{ml})$ for a week ${ }^{25}$, to simulate the long-term exposure under in vitro conditions rather than instant effects of the standard clinical application of 3\%, and the control samples were soaked with physiological saline solution for the same period with experimental group ${ }^{25}$. After a week, the samples were taken for BMD and compression tests.

\section{BMD Assessment}

BMD assessment is essential as the gold standard in evaluation of fracture risk caused by reduced bone mass ${ }^{6,26}$. The total body images of the samples were obtained with 
dual-energy X-ray absorptiometry (DEXA) scanner (GE Healthcare Lunar Prodigy) commonly used to measure BMD (grams per $\mathrm{g} / \mathrm{cm}^{2}$ ) using image captures of small animal scan software in the bone tissue from the regions of interest. BMD measurements of both the control and hydrogen peroxide exposed experimental groups are taken at 24th, 48th and 96th hours after the exposure. In order to minimize the observer related variations all analyses were carried out by the same technician throughout the process. Triplicates were taken to test the reproducibility of the measurement system. The coefficient of variation (cv) was $1 \%$. Further details of the methodology can be found in a previous study ${ }^{27}$.

\section{Compression Tests}

With the aim of establishing the operability and technical parameters, the device was subjected to comparative test trials. For comparison, the LR5K Plus universal tensile testing machine which is employed in mechanical characterization experiments. A homemade compression holder that has a diameter of $5 \mathrm{~cm}$ was clamped to universal testing machine.

Bone area subject to calculation of stress values were calculated from bone geometry using image analysis software Image J (NHI, USA). During the tests, $20 \mathrm{~mm}$ width samples prepared from bone samples were employed. The total number of test samples subjected to compression was initially 15 , composed of 7 control group and 8 hydrogen peroxide exposed samples. As seen in Figure. 2, two samples from the control group and one from the treated group could not be used due to breakage during onset of the experiment.

The samples were placed in the designed tester device and the resulting diagrams were obtained as shown in figure 2 for the LR5K Plus tester. The test results were drawn as diagrams in NEXYGEN Plus Data Analysis Software and MS Excel 2010. The vertical axis given in the diagrams are the stress values (MPa), while the horizontal axis shows the strain values ${ }^{28}$.

\section{RESULTS}

To evaluate the results, one-way analysis of variance (ANOVA) was used for statistical analysis. A p-value less than 0.05 was considered significant. For the all BMD parameters, $p>0.05$ was observed between the groups.

Figure 1 demonstrates BMD graph of the control and the experimental (hydrogen peroxide) groups. The BMD value for the control was 0.691 , while it was 0.656 ( $\mathrm{p}=$ $0.708)$ at 24th hour; these values were read as 0.682 and $0.629(\mathrm{p}=0.863)$ at the 48th hour; and at the 96th hour as 0.646 and $0.627(\mathrm{p}=0.444)$. BMD values of the control group were higher than that of hydrogen peroxide exposed experimental groups (Figure 1). But these differences were not significant.

Figure 2 shows stress-strain curves from for control and hydrogen peroxide exposed experimental groups. In compressive experiments, the maximum stress values are 16.15 MPa (C5 (Control 5)) and 10.48 MPa (HP-1 (hydrogen peroxide-1)), for control and hydrogen peroxide exposed experimental groups respectively at 0.03 strain. The lowest stress values are $7.55 \mathrm{MPa}(\mathrm{C} 2)$ and $4.54 \mathrm{MPa}$ (HP-5), for control and hydrogen peroxide exposed experimental groups, respectively at 0.03 strain (Figure 2 ). It is obvious that slopes of control curves higher than slopes of hydrogen peroxide curves. It means that hydrogen peroxide exposed experimental group has less stiffness than the control group.

Compressive moduli values for the strain (0.028-0.030) are obtained from the stressstrain curves. These are $428.87 \pm 25.83$ and $294.94 \pm 34.45$ for control and hydrogen peroxide exposed experimental group, respectively. The moduli values are higher in 
the control as compared to the experimental (hydrogen peroxide exposed) group (Figure 3). These differences were significant $(\mathrm{p}=0.016<0.05)$.

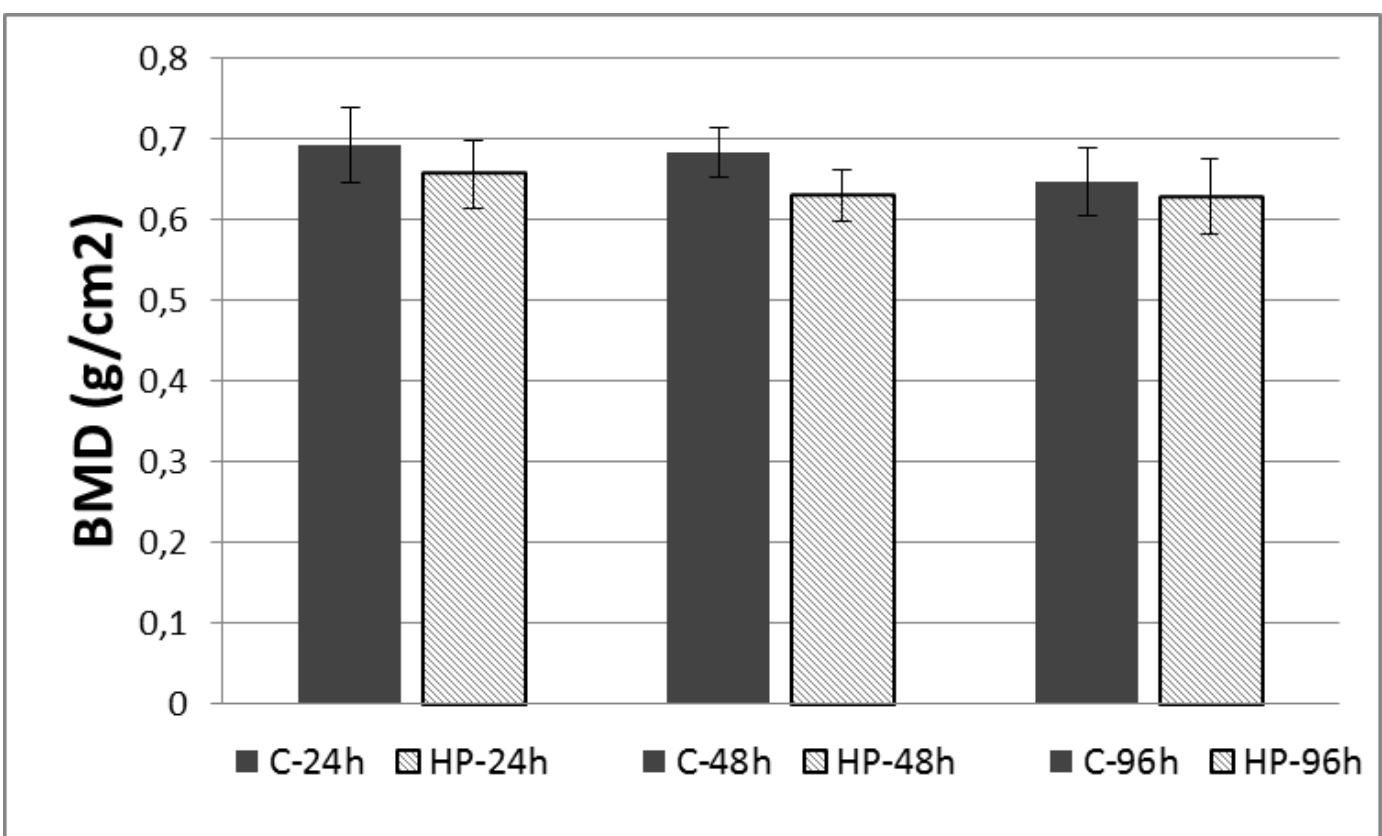

Figure 1. BMD graph of the control and the experimental (hydrogen peroxide) groups. C: Control, HP: Hydrogen peroxide

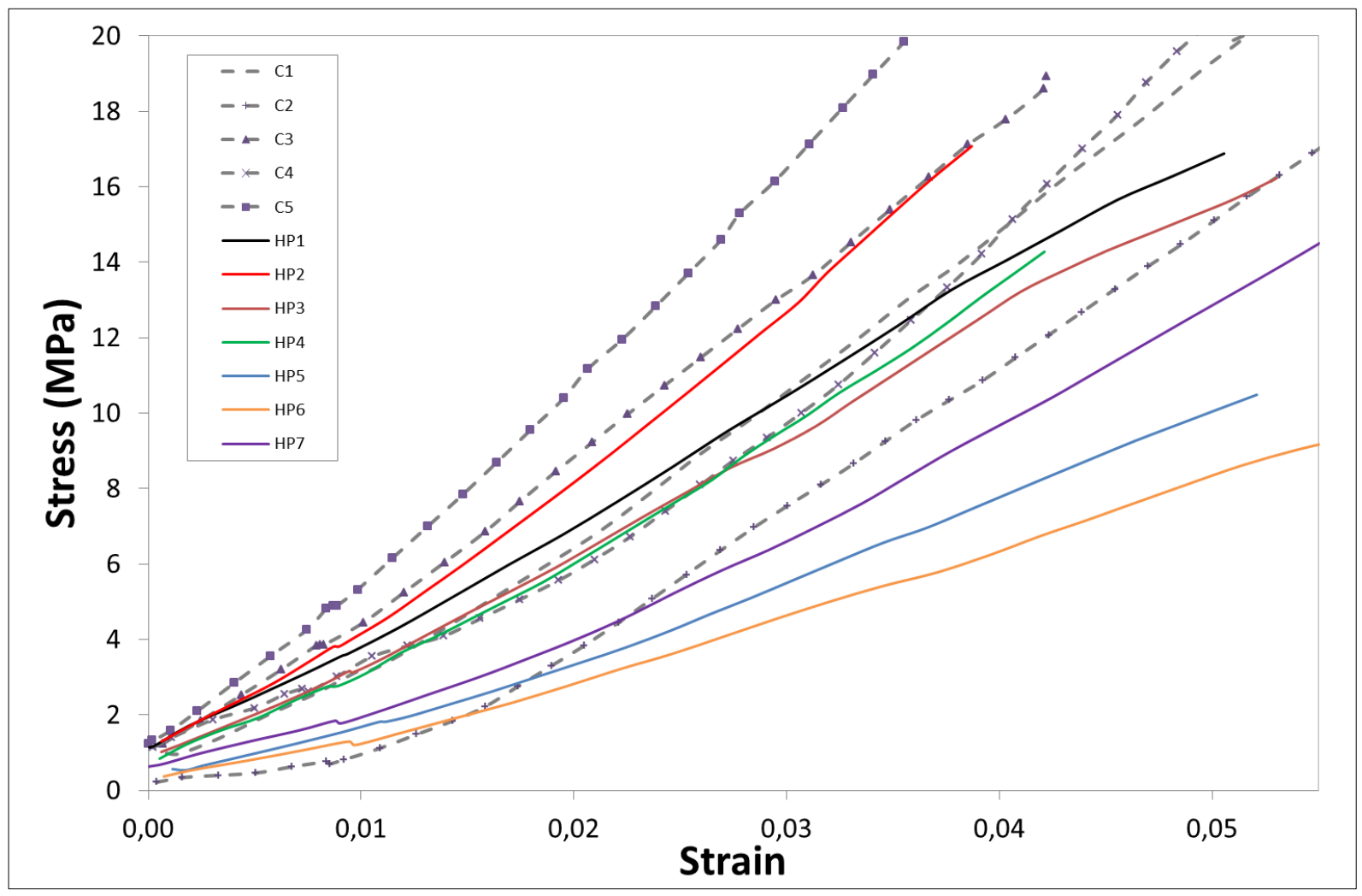

Figure 2. Representative stress-strain curves for sheep leg bone. C: Control, HP: Hydrogen peroxide 


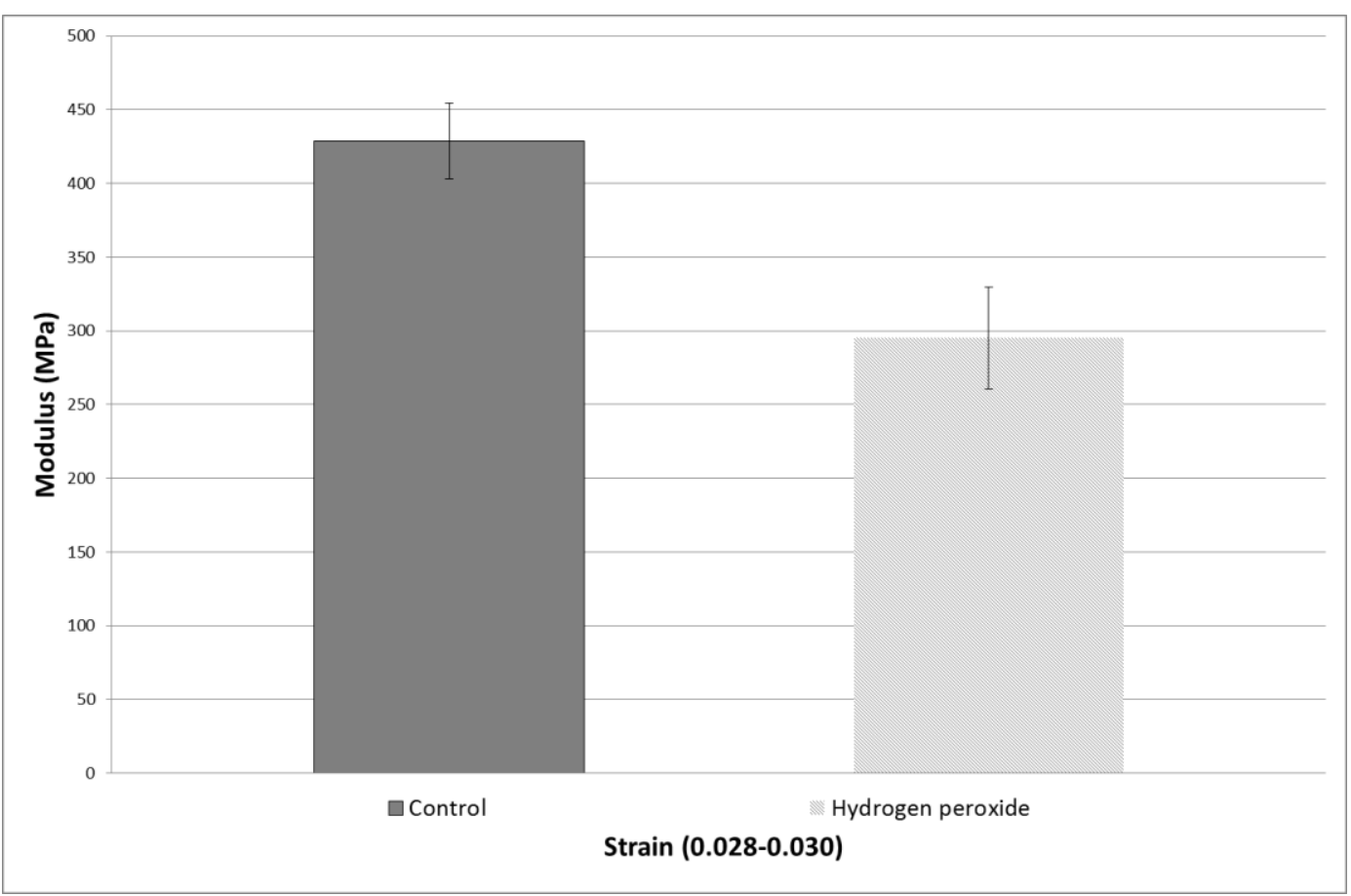

Figure 3. Modulus graph of the control and the experimental (hydrogen peroxide) groups

\section{DISCUSSION}

BMD values of the control group were higher than that of hydrogen peroxide exposed experimental groups meaning that the strength of the bone matrix is negatively affected by the oxidative damage caused by hydrogen peroxide (Figure 1), although the difference between two groups were insignificant. As seen in the graph, at the 48th hour an abrupt decrease is recorded in the experimental group and feeble decrease at 96th hour implicates the base level. On the other hand, an abrupt decline is recorded in the control after 48th hour meaning that the integrity in the medium is largely maintained till the 48th hour period.

Age-associated reduction in bone stiffness is mainly caused by collagen alterations. The decline in the reducible collagen cross-links without an alteration in collagen density is linked with increased bone fragility in osteoporosis ${ }^{17,29,30}$. Therefore, the inherent fracture risk in the osteoporosis may be induced by the decrease in stiffness independent of bone mineral density and can be prevented improving collagen structure $^{17,31,32,33}$.

Although through which mechanism hydrogen peroxide is predominantly effective on BMD is beyond scope of the present study, our BMD results indicate that as a reactive oxygen species hydrogen peroxide has degenerative effects on the stiffness of the bone.

Apart from the effects on bone matrix elements, evident in our results though not statistically significant, compressive moduli tests also reveal a significant decrease in the stiffness $(\mathrm{p}<0.05)$

The slopes of the representative stress-strain curves in our experiments control groups showed differences with that of the hydrogen peroxide exposed experimental groups (Figure 2). Therefore, we document that oxidative damage causes reduction in the stiffness of the bone.

Compressive moduli values for the strain (0.028-0.030) obtained from the stress-strain curves were clearly higher in the control as compared to the experimental group (Figure 3). 
Our results are in conformity with our previous results ${ }^{25}$ on articular cartilage. Although the determinants of degenerative processes might be different, due to the structural differences between cartilage and bone matrices, the biomechanical effects (ie in the decreased level of stiffness) are found to be similar in both tissues.

\section{CONCLUSION}

Our results indicate that oxidative damage induced by hydrogen peroxide, a common reactive oxygen species in eukaryotic cells, causes reduction in the stiffness of the sheep leg bone. The mechanism involved and interacting should be studied in the future.

\section{REFERENCES}

1. Brzoska MM, Rogalska J, Kupraszewicz E. The involvement of oxidative stress in the mechanisms of damaging cadmium action in bone tissue: A study in a rat model of moderate and relatively high human exposure. Toxicol Appl Pharmacol. 2011; 250: 327-335.

2. Kim HJ, Minashima T, McCarthy EF, Winkles JA, Kirsch T. Progressive ankylosis protein (ank) in osteoblasts and osteoclasts controls bone formation and bone remodeling. $J$ Bone Miner Res. 2010; 25: 1771-1783.

3. Altindag O, Erel O, Soran N, Celik H, Selek S. Total oxidative/anti-oxidative status and relation to bone mineral density in osteoporosis. Rheumatol Int. 2008; 28: 317-321.

4. Tiku ML, Shah R, Allison GT. Evidence linking chondrocyte lipid peroxidation to cartilage matrix protein degradation: Possible role in cartilage aging and the pathogenesis of osteoarthritis. J Biol Chem 2000; 275:20069-20076.

5. Lim LS, Hoeksema LJ, Sherin K. Screening for Osteoporosis in the Adult U.S. Population. ACPM Position Statement on Preventive Practice. Am J Prev Med. 2009; 36: 366375.

6. Smietana MJ, Arruda EM, Faulkner JA, Brooks SV, Larkin LM. Reactive Oxygen Species on Bone Mineral Density and Mechanics in $\mathrm{Cu}, \mathrm{Zn}$ Superoxide Dismutase (Sod1) Knockout Mice. Biochem Biophys Res Commun. 2011; 403: 149-153.

7. Atiyeh BS, Dibo SA, Hayek SN. Wound cleansing, topical antiseptics and wound healing. Int. Wound J. 2009; 6: 420-430.

8. Drosou A, Falabella A, Kirsner R. Antiseptics on wounds: an area of controversy. Wounds 2003; 15: 149-166.

9. Ouyang X, Wei B, Hong SD, Wang JR, Xin F, Wang L, Yang XW, Wang LM. Study on the Mechanisms of Cartilage Tissue Damage Caused by Hydrogen Peroxide. Cell Biochem. Biophys. 2015; 72: 343-348.

10. Tanaka M, Mori H, Kawabata K, Millest AJ. Minodronic acid ameliorates vertebral bone strength by increasing bone mineral density in 9-month treatment of ovariectomized cynomolgus monkeys. Bone. 2016; 88: 157-164.

11. Mody N, Parhami F, Sarafian TA, Demer LL. Oxidative stress modulates osteoblastic differentiation of vascular and bone cells. Free Radic Biol Med. 2001; 31: 509-519.

12. Ozgocmen S, Kaya H, Fadillioglu E, Aydogan R, Yilmaz Z. Role of antioxidant systems, lipid peroxidation, and nitric oxide in postmenopausal osteoporosis. Mol Cell Biochem. 2007; 295: 45-52.

13. Sheweita SA, Khoshhal KI. Calcium metabolism and oxidative stress in bone fractures: role of antioxidants. Curr Drug Metab. 2007; 8: 519-525.

14. Estai M, Suhaimi F, Shuid A. Biomechanical evaluation of fracture healing following administration of Piper sarmentosum in ovariectomised rats. Afr J Pharm Pharmacol. 2012; 6: $148-156$.

15. Lean JM, Jagger CJ, Kirstein B, Fuller K, Chambers TJ. Hydrogen peroxide is essential for estrogen-deficiency bone loss and osteoclast formation. Endocrinology. 2005; 146: 728735.

16. Lean JM, Davies JT, Fuller K, Jagger CJ, Kirstein B, Partington GA. A crucial role for thiol antioxidants in estrogen-deficiency bone loss. J Clin Invest. 2003; 112: 915-923. 
17. Burr DB. The contribution of the organic matrix to bone's material properties. Bone. 2002; 31: 8-11.

18. Liu AL, Zhang ZM, Zhu BF, Liao ZH, Liu Z. Metallothionein protects bone marrow stromal cells against hydrogen peroxide-induced inhibition of osteoblastic differentiation. Cell Biol Int. 2004; 28: 905-911.

19. Mori H, Tanaka M, Kayasuga R, Masuda T, Ochi Y, Yamada H, Kishikawa K, Ito M, Nakamura T. Minodronic acid (ONO-5920/YM529) prevents decrease in bone mineral density and bone strength, and improves bone microarchitecture in ovariectomized cynomolgus monkeys. Bone. 2008; 43:840-848.

20. Marshall D, Johnell O, Wedel H. Meta-analysis ofhow well measures ofbone mineral density predict occurrence of osteoporotic fractures. Bmj. 1996; 312:1254-1259.

21. Jacques RM, Boonen S, Cosman F, Reid IR, Bauer DC, Black DM. Relationship of changes in total hip bone mineral density to vertebral and nonvertebral fracture risk in women with postmenopausal osteoporosis treated with once-yearly zoledronic acid $5 \mathrm{mg}$ : The HORIZON-Pivotal Fracture Trial (PFT). J Bone Miner Res. 2012; 27: 1627-1634.

22. Lee YJ, Hong JY, Kim SC, Joo JK, Na YJ, Lee KS. The association between oxidative stress and bone mineral density according to menopausal status of Korean women. Obstet Gynecol Sci. 2015; 58: 46-52.

23. Husodo K, Kamal AF, Yusuf AA. Effect of povidone iodine and hydrogen peroxide on fracture healing : a histomorphometric study on rats. J Orthop Surg (Hong Kong). 2016; 24(2): 245-249.

24. Meng J, Yu P, Jiang H, Yuan T, Liu N, Tong J, Chen H, Bao N, Zhao J. Molecular hydrogen decelerates rheumatoid arthritis progression through inhibition of oxidative stress. Am J Transl Res. 2016; 8(10): 4472-4477.

25. Cicek E. Hydrogen peroxide induced oxidative damage on mechanical properties of the articular cartilage. Acta Biol Hung. 2007; 68(4): 368-375.

26. Kanis JA, Johansson H, Oden A, McCloskey EV. Assessment of fracture risk. Eur J Radiol. 2009; 71: 392-397.

27. Yildiz M, Cicek E, Cerci SS, Cerci C, Oral B, Koyu A. Influence of Electromagnetic Fields and Protective Effect of CAPE on Bone Mineral Density in Rats. Arch Med Res. 2006; 37: 818-821.

28. Cicek E. Effect of X-ray irradiation on articular cartilage mechanical properties. Acta Phys Pol A. 2016; 129: 200-202.

29. Bailey AJ, Sims TJ, Avery NC, Miles CA. Chemistry of collagen cross-links: glucosemediated covalent cross-linking of type-IV collagen in lens capsules. Biochem J. 1993; 296: 489-496.

30. Oxlund H, Mosekilde L, Ortoft G. Reduced concentration of collagen reducible cross links in human trabecular bone with respect to age and osteoporosis. Bone. 1996; 19: 479-484.

31. Hui SL, Slemenda CW, Johnston CC. Age and bone mass as predictors of fracture in a prospective study. J Clin Invest. 1988; 81: 1804-1809.

32. Langdahl BL, Ralston SH, Grant SF, Eriksen EF. An Sp1 binding site polymorphism in the COLIA1 gene predicts osteoporotic fractures in both men and women. J Bone Miner Res. 1998; 13: 1384-1389.

33. Mann V, Hobson EE, Li B, Stewart TL, Grant SF, Robins SP, Aspden RM, Ralston SH. A COL1A1 Sp1 binding site polymorphism predisposes to osteoporotic fracture by affecting bone density and quality. J Clin Invest. 2001; 107: 899-907. 